\title{
Laboreal
}

Volume $5 \mathrm{~N}^{\circ} 1$ | 2009

Ergonomia e desenvolvimento sustentável

\section{O trabalho sob um olhar sustentável - desafios para os serviços de saúde pública : Estudo de caso do Programa Saúde da Família em São Paulo, Brasil}

El trabajo desde una mirada sustentable - desafíos para los servicios de salud pública : Estudio de caso del Programa de Salud Familiar en San Pablo, Brasil Le travail sous un regard soutenable - défis pour le système de santé publique:

Une étude de cas du Programme Santé de la Famille à São Paulo, Brésil Work from the point of view of sustainability - challenges for public health system : Case study of the Family Health Program in São Paulo, Brazil

\section{Laerte Idal Sznelwar}

\section{OpenEdition}

\section{Journals}

\section{Edição electrónica}

URL: http://journals.openedition.org/laboreal/10345

DOI: $10.4000 /$ laboreal. 10345

ISSN: 1646-5237

\section{Editora}

Universidade do Porto

Refêrencia eletrónica

Laerte Idal Sznelwar, « O trabalho sob um olhar sustentável - desafios para os serviços de saúde pública : Estudo de caso do Programa Saúde da Família em São Paulo, Brasil », Laboreal [Online], Volume $5 \mathrm{~N}^{0} 1$ | 2009, posto online no dia 01 julho 2009, consultado o 10 outubro 2019. URL : http:// journals.openedition.org/laboreal/10345; DOI : 10.4000/laboreal.10345

Este documento foi criado de forma automática no dia 10 outubro 2019.

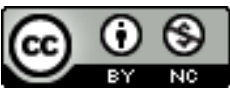

Laboreal está licenciado com uma Licença Creative Commons - Atribuição-NãoComercial 4.0 Internacional. 


\title{
O trabalho sob um olhar sustentável - desafios para os serviços de saúde pública : Estudo de caso do Programa Saúde da Família em São Paulo, Brasil
}

\author{
El trabajo desde una mirada sustentable - desafíos para los servicios de salud
} pública : Estudio de caso del Programa de Salud Familiar en San Pablo, Brasil Le travail sous un regard soutenable - défis pour le système de santé publique: Une étude de cas du Programme Santé de la Famille à São Paulo, Brésil Work from the point of view of sustainability - challenges for public health system : Case study of the Family Health Program in São Paulo, Brazil

Laerte Idal Sznelwar

\section{Introdução}

1 A discussão sobre o tema da sustentabilidade esta cada vez mais presente em nossa sociedade. Questões ligadas ao papel das empresas com relação aos impactos ambientais e à responsabilidade social estão na ordem do dia, novas normas relativas a esses temas aparecem de maneira crescente na cena pública. Entretanto pouco se fala sobre o trabalho numa perspectiva sustentável, esta questão parece que ainda não faz parte das preocupações, alias não se encontram definições sobre este tema específico no bojo da discussão do desenvolvimento sustentável. A questão do trabalho, como acontece com freqüência, fica em separado, relegada a um outro plano talvez considerado menos importante, talvez porque o trabalho teria, sob o ponto de vista da produção, um menor impacto. Em um primeiro momento seria importante tentar definir o que seria um trabalho sob um olhar sustentável. Para tanto, não seria 
necessário inventar conceitos novos, mas sobretudo se basear em abordagens já existentes que tem o trabalho como tema central de preocupações e que tratam desta questão com uma perspectiva que se inscreve em uma perspectiva de longo prazo. A proposta de discussão aqui apresentada se inspira na perspectiva da ergonomia da atividade e na psicodinâmica do trabalho que, no primeiro caso propõe compreender o trabalho com vistas a sua adaptação às características humanas, para promover a saúde, o desenvolvimento profissional e a produção. No caso da psicodinâmica do trabalho, a perspectiva de ação proposta esta voltada para a re-apropriação do sentido do trabalhar, visando, entre outros aspectos, a realização de si e o desenvolvimento do processo de identificação com o trabalho numa perspectiva da construção da saúde. Há outras abordagens que também tem contribuições significativas para o desenvolvimento deste olhar sustentável, como a ergologia e a clinica da atividade, mas estas não serão tratadas neste texto.

2 Para ajudar a embasar a proposta este artigo contém uma discussão baseada em pesquisas desenvolvidas junto a equipes de trabalho de programa de saúde pública no Brasil, o Programa Saúde da Família (BRASIL, 1998). Um dos aspectos mais significativos relacionados aos resultados desta pesquisa diz respeito à relação que poderia ser estabelecida entre o trabalho das equipes e o sucesso do programa. Isto é ainda mais importante uma vez que, por se tratar de projetos novos e em implantação ainda há muito a ser definido com relação ao escopo dos serviços e, portanto se coloca um grande desafio pois, construir um trabalho sob o olhar sustentável, significaria possibilitar o reconhecimento das ações dos sujeitos, melhor avaliar o desempenho das equipes e, sobretudo favorecer a construção de programas de saúde pública que se inscrevem no longo prazo, isto é, programas que seriam sustentáveis, uma vez que o trabalho das equipes, que são seus pilares, também o seriam.

3 Este artigo traz uma proposta inicial para debate, o tema não se esgota pois ainda há muito o que ser discutido e feito para que se possa consolidar tanto os conceitos como, também estabelecer estratégias para o desenvolvimento tanto de programas de saúde pública como, se houver um desenvolvimento deste debate, um dos objetivos maiores aqui propostos, expandir a discussão para outros setores da produção, não se restringindo a programas de saúde pública.

\section{Contribuições da ergonomia e a psicodinâmica do trabalho para um olhar sustentável sobre o trabalho}

4 Para evidenciar alguns aspectos da relação saúde e trabalho que podem ser discutidos à luz da ergonomia e da psicodinâmica do trabalho é necessário trazer para o debate as contribuições de cada abordagem. Apesar de todo o progresso que já houve para o conhecimento e para melhorias no que diz respeito ao conteúdo e à organização do trabalho graças, entre outras, às contribuições de ambas, ainda há muito o que se fazer, não apenas no que diz respeito a questões mais tradicionais, como o risco das doenças físicas, dos acidentes de trabalho, dos problemas de confiabilidade dos sistemas, mas também o desafio de evitar que continue a haver acidentes e doenças ligados ao trabalho e, ainda a aumentar os distúrbios de ordem psíquica ligados ao trabalho.

5 É notório que cada uma adota pontos de vista distintos para compreender a relação do trabalhador com o seu trabalho, mas ambas estão voltadas, à sua maneira, para o 
desenvolvimento de ações que visem a promoção da saúde e o desenvolvimento profissional dos sujeitos.

6 Um outro aspecto importante é que ao se propor a tratar da questão do trabalho, seja a partir da atividade, como é o caso da ergonomia, ou a partir do vivido pelos sujeitos, como no caso da psicodinâmica, podemos pensar que seja possível inverter a tradicional questão sobre a relação saúde e trabalho, onde este causaria quase que inexoravelmente conseqüências nefastas para os sujeitos, para um ponto de vista inscrito no longo prazo onde o trabalho seria, de fato, fonte de promoção da saúde, através da realização de si e do desenvolvimento pessoal e coletivo.

7 Neste sentido podemos recuperar a proposta de Dejours (1985) com relação à definição de saúde. Baseados neste autor poderíamos dizer que, saúde seria uma construção, um processo dinâmico, onde estaria em questão o potencial de vida dos indivíduos. Saúde não seria portanto uma aquisição, algo que, em algum momento podemos obter ou, mesmo perder, tratar-se-ia de um objetivo inscrito na vida, onde estariam em questão as possibilidades que os sujeitos tem para realizarem seus desejos e, portanto, as possibilidades para ser e agir.

8 Ao invés de propor uma definição baseada no bem estar, pois haveria uma confusão com uma idéia de estado, que seria algo fixo e determinado, poderíamos então refletir sobre o bem-estar no gerúndio, isto é, ao longo dos processos de vida. Neste sentido o termo utilizado pelos anglo-saxões seria mais adequado, pois trata-se de um "wellbeing", isto é, algo inscrito no tempo. Maggi (2006) propõe este ponto de vista, ao constituir o seu programa de pesquisa "Organisation and well-being".

9 Em ergonomia, há muitas contribuições para ajudar a desenvolver um ponto de vista sustentável sobre o trabalho. Poder agir conforme as necessidades de produção e, segundo as possibilidades de cada sujeito, que evidentemente variam ao longo da vida, seria um ponto de ancoragem fundamental. Como fazer evoluírem as condições de trabalho para que elas sejam adequáveis aos sujeitos ao longo de sua vida? Ainda mais, esta possibilidade de agir estaria ligada também às possibilidades ligadas de desenvolvimento profissional e das competências. Montmollin (1993) e Falzon (1996) propõem que aspectos cognitivos sejam considerados nos conceitos sobre a saúde. Neste sentido, um olhar sustentável, faria também referência às possibilidades que o trabalho traria para que as pessoas possam adquirir novos conhecimentos, novos saberfazer, finalmente se tornarem mais competentes.

10 Em ergonomia, apesar de não ter havido, por muito tempo, um debate mais especifico sobre o conceito de saúde que serviria como base, podemos considerar que, desde os seus primórdios, a questão da saúde como um processo dinâmico, estava colocada. Isto não estava explícito. Entretanto, ter como disciplinas fundadoras da ergonomia, a fisiologia e a psicologia, podemos compreender que a busca da adaptação do trabalho ao ser humano, considera vários aspectos da dinâmica da vida. Apesar disso, é importante frisar que à época, tanto a fisiologia como a psicologia, que serviram de base para fundar a ergonomia estavam fortemente impregnadas de conceitos mecanicistas que, propunham visões muito distantes deste ponto de vista aqui defendido, como dinâmica da vida. Por outro lado, o fato de tratar da variabilidade tanto inter como intra individual a ergonomia remete à questão da evolução dos trabalhadores ao longo do tempo, onde está incluída a questão do envelhecimento. Portanto, os autores em ergonomia mesmo sem se preocuparem inicialmente em propor conceitos sobre saúde, trilharam seus caminhos sempre trazendo novas 
questões para as disciplinas que a constituíram. Principalmente no caso da ergonomia da atividade, foi fundamental pensar os sujeitos de maneira distinta, pois os seres humanos trabalhando não são exatamente os mesmos que aqueles que estão se dispondo a participar de estudos experimentais em laboratório ou ainda, são de fato, sujeitos que agem, que refletem e que sofrem.

11 No caso da psicodinâmica, a possibilidade de agir como trabalhador estaria ligada também ao encontro entre os desejos do sujeito de bem fazer de se sentir útil, de desenvolver uma obra pessoal que o ajudaria a desenvolver seu processo de identificação, de se tornar mais inteligente. Neste caso, o trabalho como um dos pilares fundamentais para a realização de si (Dejours 2004a), teria um papel central na vida dos sujeitos. Um olhar sustentável sobre o trabalho ficaria então enriquecido por estes aportes relativos à racionalidade pática.

Repensar os paradigmas significa também repensar o que é o trabalho, significa possibilitar que as pessoas tenham trabalhos interessantes e desafiadores. Seria interessante questionarmos quantas pessoas tem o privilegio de desenvolverem trabalhos que lhes permite se desenvolver profissionalmente e trilhar caminhos de realização de si. Segundo Murphy (1993), boa parte das pessoas nos Estados Unidos, consideravam, à época, que o trabalho que desenvolviam era desinteressante.

A partir desta pequena explanação, poderíamos afirmar que é importante considerar que a questão da saúde está colocada pelas possibilidades que o trabalho propiciaria para as pessoas desenvolverem as suas atividades. São necessários projetos de produção e de maneiras de gestão do trabalho que incluam as pessoas como sujeitos e não como extensões de máquinas, ou ainda, como a parte do sistema que pode se adaptar, se adequar aos dispositivos técnicos. Possibilitar o desenvolvimento e não impedir as ações seria então um passo fundamental para se alinhar numa perspectiva de um trabalho sustentável.

\section{Ergonomia e psicodinâmica do trabalho - um dialogo baseado em conceitos e abordagens distintos}

Construir um diálogo entre disciplinas distintas como a ergonomia e a psicodinâmica do trabalho requer, em primeiro lugar, distinguir os pontos de vista que as fundamentam para, depois buscar o que ha em comum e o que ha de divergências.

É importante que se busque esclarecer um pouco mais estas questões, sobretudo porque apesar do sujeito que trabalha ser único quando trata-se de considerá-lo como indivíduo, não há um ponto de vista que possa dar conta das mais diversas propriedades humanas. Isto não significa que seja possível propor que haja uma fusão de abordagens, até porque os pontos focalizados são distintos, as disciplinas de base não são as mesmas, como também não o são as propostas de ação. No caso deste artigo, importa sobretudo trazer para o debate aquilo que possa ajudar na constituição de um olhar sustentável, mesmo que este seja oriundo de pontos de vista diversos.

Lembramos que, o desenvolvimento das ciências está baseado na distinção, ou ainda mais, na disjunção, cada uma trata de seu objeto de estudo e, muitas vezes desconhece completamente os pontos de vista que governam uma determinada área do conhecimento (Morin, 1998). 

fazem, como cada sujeito usa de si para realizar aquilo que foi previsto nas tarefas e, também aquilo que não foi previsto, para se obter os resultados de produção almejados. O sujeito em ergonomia, não é muito bem definido, usase normalmente o termo como operador, talvez ainda uma herança de tempos mais positivistas. Se considerarmos como sujeito, este o seria um sujeito da ação, um sujeito agente, se for emprestado o ponto de vista de Maggi (2006). Para a ergonomia, o sujeito agente seria constituído com base em conceitos da fisiologia e da psicologia cognitiva, com alguns empréstimos da sociologia e da antropologia.

18 É objetivo fundamental da ergonomia, cooperar para que se forneça as mais adaptadas ou adaptáveis, condições para que o sujeito consiga desenvolver bem a sua atividade, portanto as suas ações estarão voltadas para propiciar cenários onde os trabalhadores possam atingir objetivos diversos como alcançar ou até ultrapassar metas de produtividade e qualidade, desenvolver a sua saúde e se desenvolver profissionalmente. O foco de ação a ser desenvolvida está no projeto das máquinas, das ferramentas, da organização do trabalho, dos processos de produção e do conteúdo das tarefas. Ações relativas aos processos da gestão da produção e do trabalho ; assim como aos processos de treinamento e aprendizagem, também estão no seu escopo.

19

Assim sendo, há um vasto campo de ação para a ergonomia. De modo mais tradicional, há ainda muito que se fazer no âmbito do conforto físico ; da prevenção à fadiga ; da prevenção de problemas de saúde. Para tanto há todo um campo para a adequação de projetos voltados para os ambientes, os postos de trabalho; as máquinas e ferramentas; a organização dos tempos e do conteúdo das tarefas. Outros temas que ainda são do escopo da ergonomia dizem respeito à facilidade no uso dos artefatos ; às estratégias operacionais, ao desenvolvimento da inteligência, à facilidade de leitura, às linguagens e as comunicações; aos sistemas de cooperação; à confiabilidade dos sistemas ; à capacitação e à aprendizagem. Ainda, e de maneira cada vez mais presente, há questões a serem tratadas, que sempre fizeram parte das preocupações da ergonomia, como, a adequação do trabalho a populações as mais diversas, incluindo a questão do envelhecimento e do gênero ; a inclusão no mundo do trabalho de pessoas que tenham necessidades especiais (Béguin, 2006 ; Carayon, 2006 ; Imada, 2005 ; Kleiner, 2006 ; Kogi, 2006 ; Rabardel \& Béguin, 2005).

20 A perspectiva é que os conceitos e as modalidades de ação em ergonomia possam ser incorporados aos projetos e à gestão nos mais variados setores da economia, objetivo mais ou menos explícito, o de transformar a ação mais tradicional da engenharia, onde, a atividade humana de trabalho seja considerada como um dos pilares fundamentais de qualquer projeto e não como uma variável de ajustamento para ser tratada quando praticamente tudo já está definido e faltaria apenas encaixar os trabalhadores adequados (Guérin, Laville, Daniellou, Durrafourg, Kerguelen, 2001 ; Hubault, 2004a ; Noulin, 1992 ; Terssac \& Maggi, 2004).

21 Já no caso da psicodinâmica do trabalho, se considerarmos os trabalhos ainda em psicopatologia do trabalho, desenvolvidos por Dejours (1987) no início da década de 80, havia uma proposta de se considerar esta abordagem um dos pilares a serem tratados pelas disciplinas focadas no trabalho, principalmente porque havia uma vazio epistemológico para ajudar a explicar um enigma encontrado pelo autor que seria a quase inexistência de doenças mentais em trabalhadores sujeitos a trabalhos fragmentados, repetitivos e desprovidos de conteúdo simbólico. Por outro lado, deveria 
haver algum sofrimento de ordem psíquica para estas populações de trabalhadores; inclusive porque este tipo de questão já havia sido mostrada por Le Guillant \& col (1984), no caso das telefonistas.

Outro tema intrigante seria a existência de certos tipos de comportamento inusitados desenvolvidos pelos trabalhadores frente a situações de risco, onde não aparecia, claramente, o medo relativo à possibilidade de se acidentar. Toda uma discussão é proposta pelo autor, relativa aos mecanismos de defesa psíquico, individuais e coletivos (ideologias defensiva) para explicar estes fenômenos (Dejours, 1987).

Em suma, os temas em psicopatologia do trabalho, desde os seus primórdios, estavam voltados para tentar explicar esta aparente "normalidade". Isto foi possível, a partir da discussão publica sobre os mecanismos de defesa individuais e coletivos, construídos para dar conta da incompatibilidade entre o desejo dos sujeitos e os constrangimentos impostos por modalidades de organização do trabalho. Portanto, haveria um risco para a existência do sujeito, tanto em nível simbólico, como no que diz respeito aos riscos para a sua integridade física, como é o caso, por exemplo, do sofrimento e das patologias ligadas a certos tipos de organização e conteúdo do trabalho (Sznelwar e Massetti, 2002).

Por outro lado, há estudos que mostram, em certas situações onde a profissão dos trabalhadores era valorizada, a existência de comportamentos de prudência aliados ao saber-fazer das profissões (Cru e Dejours, 1983).

A evolução dos conceitos na área, inclusive com a adoção do nome psicodinâmica do trabalho, propiciou a inclusão do sofrimento e do prazer como conceitos que permitem entender a relação dialética dos sujeitos com o seu trabalhar (Dejours, 2004b). Isto não anula aquilo que já havia sido descoberto antes, mas trouxe uma ampliação significativa do campo.

26 Ao discutir a relação sofrimento e prazer, a psicodinâmica do trabalho propõe também algumas distinções. No caso do sofrimento, poderíamos considerar o sofrimento que resultaria em motivação para que os sujeitos desenvolvam novas soluções, novas estratégias, novos acordos de cooperação, isto quando o conteúdo e a organização do trabalho permitem suficiente margem para tal. Neste caso, o sofrimento inicial poderia resultar em prazer, em realização. Entretanto, nos casos em que há um bloqueio da organização do trabalho e as tarefas têm o seu conteúdo esvaziado haveria uma tendência para que esse sofrimento se tornasse patogênico, possibilitando o aparecimento de problemas de saúde expressos na economia somática e/ou psíquica.

As questões centrais em ergonomia para promover o envolvimento dos trabalhadores nos processos de análise e síntese são: o que fazem, como fazem, quais dificuldades encontram e como as superam e o quê fazer para melhorar ; no caso de uma ação em psicodinâmica o como ponto de partida para o encaminhamento dos trabalhos junto com os trabalhadores seria o de como vivem o seu trabalho e o que este significa para eles (Dejours, 2004b). No que diz respeito ao sujeito, à subjetividade e à intersubjetividade, a psicopatologia e a psicodinâmica do trabalho tem sua origem em conceitos e na abordagem psicanalítica (Dejours, Abdoucheli, Christian, 1994). Estas questões se constituem em pilares fundamentais para a compreensão de como as pessoas vivem o seu trabalhar.

Portanto, os temas principais que sobressaem em psicodinâmica são os sentimentos relacionados à realização de si, ao reforço do processo da identificação como sujeito 
participante de um determinado coletivo de trabalho, à compaixão, ao sentimento de justiça e ao reconhecimento (Lancman \& Uchida, 2003). Ainda, a questão da diferença no que diz respeito ao gênero é significativa neste campo (Molinier, 1995).

Ainda, no campo das abordagens que se ocupam do trabalho, há outras abordagens maneiras de tratar a subjetividade, como aquela inspirada em um ponto de vista histórico cultural, oriundo de Vigotsky, a clinica da atividade, proposta por Clot (1999). Em ergonomia, na grande maioria dos casos, a referência ao sujeito que trabalha foi feita como "operador", designação que não invoca a subjetividade ou mesmo a existência de um sujeito especifico. Hubault (2008), propõe uma discussão sobre a questão da subjetividade em ergonomia, considerando que trabalhar é experimentar aquilo que acontece, é se arriscar, seria desenvolver sua capacidade de agir. $O$ ponto de vista proposto por este autor aproxima os temas da ergonomia daqueles propostos pela psicodinâmica do trabalho, principalmente quando ele afirma que a subjetividade estaria ligada a como aquilo que fazemos nos afeta, de como somos mobilizados por aquilo que gostaríamos de fazer.

Com relação aos objetivos na ação, apesar de não haver oposição entre as duas abordagens, as propostas e a prática desenvolvida são distintas. Para a ergonomia, é fundamental desenvolver uma maneira de agir que redunde na transformação do trabalho ; neste caso o envolvimento dos trabalhadores é estratégico para favorecer não apenas uma melhor compreensão da atividade, como também para desenvolver melhores projetos. Esta ação envolveria outros atores nas empresas e o papel da ergonomia seria o de introduzir em uma lógica de projeto e de gestão, a atividade de trabalho. A ação transformadora proposta pela psicodinâmica do trabalho estaria voltada para o reforço ou para a re-apropriação do sentido do trabalhar pelos trabalhadores, favorecendo uma transformação individual e do coletivo com uma perspectiva de ações efetivas no mundo do trabalho (Molinier, 2001). Neste caso, as ações, tanto em ergonomia como em psicodinâmica do trabalho, estariam inscritas, de maneiras distintas, as racionalidades citadas por Daniellou, quando o autor se refere a domínios da ação : o da racionalidade instrumental, o da racionalidade axiológica ; o da racionalidade pática e o da racionalidade comunicacional (Daniellou, 1996).

31 No âmbito das ações em ergonomia, há uma atenção voltada para um resultado concreto no que diz respeito aos meios, à organização e ao conteúdo do trabalho. Neste sentido, é pragmática, ao propor uma transformação que propicie melhores condições para os trabalhadores. Nesta perspectiva, há duas questões em sentido inverso que se colocam. Em primeiro lugar, seria a perenidade das transformações. É evidente que as situações de produção são dinâmicas que há mudanças constantes, caberia saber, no caso da ergonomia, o quanto o ponto de vista da atividade de trabalho se torna um dos aspectos estratégicos para a concepção e para a gestão da produção, pois de pouco adianta fazer alguma transformação nas condições de trabalho se, estas poderão ser revertidas por alguma ação gerencial contraditória ou ainda, se não houver, de fato, uma incorporação de que trabalhar melhor seria, de alguma forma, agregar mais valor. Por outro lado, qualquer ação que envolva outros atores sociais, tem impacto sobre os sujeitos envolvidos direta ou indiretamente com estes processos. Neste sentido, a ação em si já teria um caráter transformador. Isto aumentaria a responsabilidade das pessoas envolvidas na condução de uma ação em ergonomia, pois dependendo do seu posicionamento, seria facilitado ou dificultado um envolvimento efetivo dos atores. 
No caso de uma ação em psicodinâmica do trabalho, os objetivos não estão diretamente ligados a transformações concretas no trabalho. Este tipo de ação visa, sobretudo criar um espaço de livre circulação da palavra que facilite uma ação coletiva de reapropriação do sentido do trabalhar, um processo de emancipação. Isto teria como resultados uma transformação na relação dos trabalhadores com o seu trabalho, principalmente no que diz respeito à vivência da relação sofrimento / prazer. Isto se reveste de uma importância ímpar, ainda mais, frente a formas de organização do trabalho que privilegiam a individualização e o isolamento dos indivíduos. Ainda é importante salientar que, na grande maioria dos casos, o sofrimento trazido pelas maneiras como o trabalho é organizado, como as pessoas são avaliadas, são vivenciados individualmente e, assim o que a pessoa sente fica mais no registro da usa fraqueza de sua incompetência, de sua inadequação. Os insucessos seriam creditados ao indivíduo unicamente e não a problemas do próprio sistema de produção. Por isso, a ação em psicodinâmica é baseada na criação de grupos de expressão onde se discutem as experiências vivenciadas no trabalho e, ao mesmo tempo, onde a própria dinâmica dos grupos resulte numa experiência de mudança e transformação, isto é, em um movimento que vise ações transformadoras sobre a maneira de trabalhar.

Em suma, é proposta a criação de um "espaço público" de discussão conforme proposto por Arendt (1987) e adotado por Dejours (2004c) na abordagem da psicodinâmica do trabalho, que pode ser considerada como um ponto de partida para que possa haver mudanças mais profundas não só na relação do sujeito com o seu trabalhar, mas sobretudo, uma transformação conduzida não apenas pelo coletivo que participa destes grupos, mas também, por outros colegas, que participariam de um processo de validação ampliada dos resultados obtidos no grupo que originou a ação.

\section{Apresentação e discussão da metodologia e dos resultados da pesquisa}

A ação ergonômica A partir da demanda, relativa à necessidade de expandir o Programa Saúde da Família, foi iniciado o processo de análise visando explicitar a natureza da problemática e, as possibilidades, tanto para o desenvolvimento da ação ergonômica quanto para possíveis melhorias no programa. No processo da análise da demanda foram entrevistados diferentes atores, definidos os interlocutores, os momentos quando seria possível interagir, as modalidades de observação possíveis, a composição de grupos de análise e discussão e, também como seriam desenvolvidas as validações junto aos atores envolvidos. Em seguida, através de documentos e de entrevistas foi estudado o contexto operacional e a produção, a inserção do PSF no âmbito do SUS e as diferentes instituições co-ligadas ao sistema. Foram levantados dados sobre os processos técnicos e as etapas do serviço que compõem o atendimento da população. Em seguida, foram tratadas as questões ligadas à definição das tarefas e as características dos locais onde foi feito o estudo (três Unidades Básicas em cidades diferentes, São Paulo, Riberião Preto e Embú das Artes). Em seguida foi feito um levantamento demográfico das equipes de trabalho. A análise das atividades foi feita, em conjunto com as equipes, foram criados grupos de discussão sobre as atividades desenvolvidas nas equipes e feitas observações do trabalho nas situações onde foi possível. Ressalte-se que, grande parte das atividades não puderam ser observadas devido a questões ligadas ao sigilo profissional e à dificuldade de acesso à residência das 
pessoas, desta forma, muitos dados foram obtidos e, posteriormente validados, a partir das discussões com as equipes.

No caso da ação em psicodinâmica do trabalho, foram feitas apresentações para as equipes de trabalho das três Unidades Básicas de Saúde estudadas e foi solicitada a adesão de voluntários para participarem dos grupos, cada categoria profissional desenvolveu o seu grupo em separado. Neste momento foram apresentados os objetivos da ação proposta e, também foram levantados junto aos participantes desta explanação, questões que ajudaram a analisar as demandas dos grupos. Para o desenvolvimento desta ação foi acordado junto com os gestores e com as equipes do programa na UBS estudada em São Paulo quais seriam os horários onde haveria um menor impacto com relação à produção do serviço e que fosse possível para os voluntários estarem presentes. Neste caso foi feito o processo completo, isto é, cada grupo se reuniu por aproximadamente dezoito horas distribuídas em até seis sessões em acordo com as possibilidades de reunir os grupos de trabalhadores. As sessões foram registradas e o material de cada uma foi analisado em reuniões anteriores às sessões seguidas. Foi redigido um relatório final para cada grupo, validado na última sessão. Nas outras duas unidades, foi feita a leitura deste relatório, em um processo de validação ampliada, onde foram acrescentadas novas vivências destes trabalhadores. Em seguida os relatórios foram entregues aos participantes dos grupos e aos gestores.

\section{Resultados}

Um dos principais desafios para a implantação de um programa desta magnitude, e entender o trabalho e vislumbrá-lo numa perspectiva sustentável, uma vez que dentre os seus objetivos, destaca-se que ele deverá ser implantado em todas as cidades do Brasil e, se tornar a principal porta de entrada para o Sistema Único de Saúde, a serviço de toda a população. Compreende-se a magnitude deste desafio se considerarmos a extensão territorial do país, uma população de quase duzentos milhões de pessoas que tem necessidades as mais variadas, devido às diferenças regionais, os riscos à saúde ligados às condições materiais de vida e, também pelo acesso a toda uma gama de serviços públicos essenciais, como o acesso à água, esgotos, transporte e educação.

o Programa Saúde da Família, doravante será designado como PSF, prevê toda uma série de ações voltadas para o atendimento, prevenção e promoção da saúde. Neste sentido, todo um espectro de ações são possíveis; no caso do atendimento, estaria previsto, que pudessem ser resolvidos a grande maioria dos problemas de saúde, uma vez que o sistema de atendimento seria capaz de atender às doenças mais corriqueiras e, quando necessário, utilizar um sistema de referencia e contra-referência para o acesso a especialistas, a atendimento hospitalar e a exames de auxílio ao diagnóstico. Seria então um sistema integrado de atendimento que teria também todo um conjunto de ações de prevenção, baseadas em práticas já existentes no Sistema Único de Saúde, como no caso da prevenção primária, as vacinações, entre outras. Na perspectiva do desenvolvimento de atividades de promoção da saúde, estão previstas ações educativas, culturais e de apoio às famílias para que possam construir melhores condições de vida. Cabe ressaltar que o programa deve ser implantado em dois sentidos. Ao mesmo tempo que a população teria acesso às unidades de atendimento do programa, os profissionais também teriam como papel o de ir até as famílias para desenvolver as ações propostas, principalmente as que dizem respeito à prevenção e à promoção. É nesta perspectiva 
que o programa inclui na equipe de trabalhadores uma nova figura, a do Agente Comunitário de Saúde (doravante chamado de ACS).

O PSF traz como proposta, mudanças significativas para os trabalhadores das equipes de saúde. Há uma tentativa de integração de ações, que não havia antes no Sistema de Saúde. Desta maneira, ao tratar dos diferentes níveis de intervenção dos profissionais das equipes PSF e de outros atores do sistema, há uma questão fundamental que estaria ligada ao papel de coordenação das ações. Quem seriam os responsáveis por assegurar que esta integração seria de fato construída. Em princípio, por estarem em contato direto com a população e por terem a responsabilidade de cuidar de aspectos distintos desde a promoção até a atenção, as equipes PSF estariam em condições de coordenar a integração das ações de saúde em diferentes níveis. Entretanto, ainda há muita dificuldade para se conseguir de fato uma integração das ações e também o papel de coordenação a partir do PSF não é uma prática disseminada.

Dentre as questões que se colocam para que o PSF se torne um projeto mais consolidado esta ligado ao fato que a sua implantação requer muitas mudanças, pois há uma exigência grande no que diz respeito à atuação de cada profissional das equipes. 0 conteúdo do trabalho e a maneira como são organizadas as equipes é muito distinta daquela tradicional e, isto requer a capacitação de todos, inclusive porque, nas escolas há uma forte tendência à formação de profissionais de saúde baseada em um modelo baseado na centralidade dos hospitais. Há, portanto, uma dissonância entre a expectativa das relações de trabalho e a realidade do PSF (Sznelwar e Abrahão, 2007a).

Ressalte-se que o PSF é concebido em torno da família e que a visita domiciliar é um dos pilares do sistema. Também a questão do território, do lugar onde o programa deve ser implantado, é importante. As ações das equipes estão circunscritas a um determinado território (Brasil, 1998). Isto reforça um dos desafios grandes do sistema, que é a imensa variabilidade devida às enormes diferenças existentes. O sistema, apesar de ser uma proposta única, tem sua gestão descentralizadas, cada município é responsável pela operação e própria constituição do programa em seus diversos distritos e bairros.

O PSF não é necessariamente uma novidade em termos de organização de serviços de saúde no Brasil. Segundo Silveira (1999) o foco na família já existia em outros programas. A novidade seria organizar um serviço que tem contato constante com as famílias, uma vez que o projeto propõe que haja visitas domiciliares freqüentes, e que haja um constante processo de vigilância epidemiológica. Isto traz um desafio significativo no que diz respeito à obtenção de dados e sobre a decisão com relação a quais indicadores de saúde são relevantes e sensíveis para se avaliar os resultados das ações do programa.

42 Apesar de haver um modelo de intenções, de preceitos e princípios norteadores, o PSF foi e está sendo uma experiência em construção. Nesse sentido, não há uma especificação única de operações dos serviços a ser seguido, nem definições claras dos papéis dos diferentes profissionais envolvidos, tampouco um pacote de serviços e de procedimentos anteriormente definido para ser aplicado. O que se encontra é uma infinidade de situações diferentes em cada família, rua, bairro, cidade, enfim, uma enorme variação de condições de vida e de condições de trabalho no sistema.

Outro aspecto significativo refere-se às mudanças nos papéis tradicionais dos profissionais envolvidos, principalmente nos dos médicos, nos profissionais de enfermagem e nos agentes administrativos. No seio das equipes as relações ainda estão por serem construídas, o PSF abriga novidades significativas. Nesta perspectiva esses 
profissionais precisam re-criar, a sua atuação profissional e as relações nas equipes. Além disso, a presença de um novo ator, o ACS, traz novas questões para os profissionais da saúde e para as equipes. Para os ACS há todo um caminho a percorrer e a trabalhar dentro da ambigüidade da sua situação: profissional da saúde ligado ao estado ou alguém da comunidade que tem um papel junto à saúde pública?

Há, portanto, uma significativa mudança temporal e geográfica. O PSF se espalha no tempo e no espaço, a relação com as famílias e com a comunidade, reflete o ciclo de vida das pessoas enquanto sujeitos e enquanto membros de coletivos diversos.

Com relação aos aspectos organizacionais do trabalho no PSF há vários aspectos importantes que foram discutidos por Silva, Silveira, Quaggio, e Colameo (2007). Os autores fazem um análise do programa baseados em alguns pressupostos relacionados aos conceitos de serviço onde fica patente a dificuldade para, em primeiro lugar conceber o sistema e, em um segundo momento desenvolver os processos de gestão do programa.

46 Para esses autores há uma questão fundamental ligada ao fato do serviço em saúde ser algo muito pouco tangível, ainda mais que a questão da saúde se inscreve no muito longo prazo. Outro aspecto fundamental está no fato que as ações do PSF não se bastam, elas se completam com outras ações que devem ser providas por outros atores ligados tanto à iniciativa pública como privada. Neste sentido, a criação de uma rede de serviços distintos e, principalmente a integração destes é que podem garantir a qualidade e a perenidade deste tipo de programa.

Ao analisar os resultados desta pesquisa, e considerando as abordagens utilizadas, Sznelwar e Abrahão (2007a), afirmam "que as ferramentas para compreender e avaliar as ações desenvolvidas e os serviços prestados devem considerar, sobretudo que é necessário tempo para que se possa tecer essas relações e, para que a população se aproprie do PSF como uma possibilidade para mudar significativamente o Sistema de Saúde".

No ponto de vista da organização do sistema é importante que se possa definir, quais são as tarefas dos diferentes atores do sistema. No caso do PSF, o grau de formalização através de procedimentos é bastante baixo, há um ampla margem de manobra para que, em cada situação, baseados nas necessidades locais e nos preceitos de cada profissão, se defina o modo de atuação das equipes. Neste caso, há uma grande amplitude no que diz respeito às margens de manobra para que as equipes possam adequar os procedimentos à realidade e à sua condição fisiológica e psicológica. Por outro lado, fica difícil para os gestores locais e para os trabalhadores, saberem quais seriam os limites do seu trabalho. Por exemplo, é difícil saber até que ponto eles vão, como se pode delimitar o campo de atuação do programa. Se por um lado, esta amplitude de margem de manobra traz, uma vantagem no que diz respeito ao trabalho profissional, pois deixa um espaço discricionário para que se adaptem as ações, há um risco significativo pois nunca se sabe se aquilo que se fez é suficiente, se as ferramentas colocadas à disposição dos trabalhadores bastam, se os treinamentos são suficientes e adequados.

49 Para Silva, Silveira, Quaggio, e Colameo (2007), é importante conhecer o fluxo de serviços para as demandas específicas dos usuários, identificar se recebem serviços de outras instituições e qual o papel da organização estudada nesta rede. No caso do PSF, seria importante situar o programa dentro do Sistema Único de Saúde e, também no âmbito das diferentes ações ligadas a outros serviços e equipamentos a serviço da 
população para que se possa entender os mecanismos de coordenação entre as diferentes organizações que cooperariam para que se propicie serviços de qualidade para a população. Ainda para estes autores, "a autonomia proporcionada pela municipalização dos serviços de saúde resultou naturalmente em processos de implantação de modelos distintos de gestão e operação de serviços de saúde, marcados pela grande experimentação local de práticas e adoção das estratégias consideradas mais adequadas pelos gestores municipais." Entretanto, baseados nos resultados da pesquisa, os autores mostram que há pontos em comum que devem ser considerados para que se possa melhor avaliar o PSF. Dentre as dificuldades para a sua implantação, ressaltam que a população ainda demanda um modelo tradicional, estruturado nos moldes do pronto atendimento; que há dificuldades de adaptação e capacitação dos profissionais ao modelo implantado pelo PSF; e ainda que há dificuldades para se constituir de fato, uma cooperação para o trabalho em equipe. Ressaltam ainda que há uma sobrecarrega de trabalho de trabalho devido à demanda reprimida, uma vez que as equipes se ocupam de um numero maior de famílias que aquele estipulado pelo PSF e que as atividades de retaguarda também estão prejudicadas devido a baixos níveis de informatização que obrigam os trabalhadores a despenderem muito tempo com processos administrativos, que concorrem com as atividades fins. Ressalte-se que são as mesmas pessoas que desenvolvem as tarefas de acolhimento, atendimento, visitas, entre outras tantas e, ainda fazem o trabalho de preenchimento de formulário, agendamento, entre outras tarefas administrativas.

\subsection{Discussão dos resultados da Análise Ergonômica da Atividade (baseada em Mascia et al, 2007)}

50 As equipes de base no PSF são constituídas por médicos (1), enfermeiros (1), auxiliares de enfermagem (2) e agentes comunitários de saúde ACS (5 a 6). Os programas e os horários relativos às atividades a serem desenvolvidas são definidos pelas equipes que se reúnem a cada semana, ajustes também são feitos conforme as necessidades do dia ou mesmo do momento. É importante levar em conta que as equipes atuam dentro da Unidade Básica de Saúde e na comunidade onde estão inseridas, desta forma, é fundamental que haja um balanceamento das atividades e o trabalhador que mais atua na área e, que também tem um papel de articulação é o ACS. Cada profissional desempenha os papéis previstos na sua profissão, além de desenvolver atividades integradas com outros colegas que, muitas vezes, superam os papéis tradicionais, pois é importante atuar em atividades de promoção da saúde que não correspondem a um visão assistencialista mais tradicional, isto é, a de receber as demandas na unidade de saúde e medicar.

51 Atuar em equipe no PSF significa articular e colocar em jogo as competências de cada profissional e, ainda desenvolver novas, tanto no que diz respeito a atuação de cada profissão, como na construção de novas competências, não aprendidas na escola. Neste caso, a situação do ACS é ímpar, uma vez que, segundo a perspectiva prevista no programa, trata-se de pessoas que devem viver na comunidade. Estes trabalhadores, para serem admitidos, não precisam ter competências específicas em saúde, mas devem ter o segundo grau completo (nível do Bac francês). O papel deles é de suma importância pois são o elo de ligação e, também são eles que desenvolvem as açães junto à comunidade. Como tudo é novo, a sua atuação não é muito definida, e ela é 
construída a partir das necessidades da comunidade, dos objetivos gerais do programa, das competências da equipe e daquilo que se sentem capazes.

Um fato significativo está no aumento constante das demandas de serviço, segundo os integrantes das equipes, há toda uma demanda reprimida que, ao se propor o acesso a um serviço integrado, como o proposto no programa, todas as necessidades da população florescem quase que de uma só vez. 0 dilema das equipes está em dar conta das atividades propostas no nível das suas atribuições, que também não estão muito claras, é necessário tentar articular com outros níveis de assistência à saúde, como o acesso a especialistas e a exames complementares, fato que lhes ocupa de maneira significativa, pois o sistema não comporta esta demanda.

53 Trabalhar como ACS exige um constante re-planejamento de suas ações, há muitos eventos que ocorrem durante a jornada de trabalho que interferem no curso de suas ações. Por exemplo, uma visita pode ser mais longa, há um afluxo muito grande de pessoas na unidade de saúde impedindo a sua saída, entre outros. Além do mais, os meios de trabalho não são suficientes e adequados para que eles consigam desenvolver com mais facilidade o seu trabalho. No caso do tratamento e armazenamento de informações há uma carência de materiais informatizados e os programas disponibilizados não foram concebidos a partir de um conhecimento mais profundo sobre as atividades destes profissionais e da equipe como um todo. São muitas informações que devem ser trabalhadas, os ACSs precisam conhecer bem a população adscrita e, sobretudo eles precisam acompanhar cada integrante das famílias para saber se há alguma ação prevista ou a propor. Em suma, parte importante do seu trabalho é a de criar vínculos com a população.

Como em qualquer relação de serviço, o papel do usuário interfere de maneira significativa no curso da ação destes trabalhadores. Este tipo de trabalho tem como peculiaridade o fato de que estes profissionais, e também o restante da equipe, se relacionam com as pessoas da comunidade acompanhando todo o ciclo de vida, desde o nascimento até a morte. Além disso, a maneira como se organizam as comunidades, interfere de maneira significativa no seu trabalho. Cada rua, cada pedaço do bairro, pode ser muito distinto, no que diz respeito à urbanização mas também com relação aos diferentes grupos que se organizam. Há casos em que o trabalho pode ser facilitado ou dificultado, dependendo de como são constituídas as relações de poder no local. (ex. : necessidade de ter autorização de integrantes de quadrilhas do crime organizado para visitar os locais ; contar com o apoio de associações religiosas para conseguir melhorar o contato com a população).

O rol de atividades de um ACS envolve ações que se dão dentro das unidades de saúde, como o acolhimento das pessoas, pois é necessário que elas sejam orientadas e acompanhadas durante os processos que aí ocorrem. Isto inclui também ajudar na coleta de exames. Este acolhimento também inclui o de pessoas que estão em situação difícil, apesar de não ser o objetivo, há pessoas que chegam em estado de saúde agravado, necessitando de atendimento de urgência, com alterações do seu estado mental, com necessidade de encontrar alguém para conversar, em suma, pode acontecer uma gama significativa de situações, onde para cada uma, é necessário agir conforme para tentar resolver o problema que se apresenta. Isto exige mudanças constantes na maneira de agir e o desenvolvimento de estratégias individuais e coletivas para tentar evitar que haja um agravamento do estado da pessoas. 
56 Ainda faz parte do seu trabalho, participar de grupos educativos e de ações concentradas, organizadas pela Secretaria Municipal de Saúde visando algum tipo específico de atendimento (por exemplo : fazer ultrassonografia para todas as mulheres grávidas daquela região em um determinado fim de semana).

57 Mesmo que parte importante de seu trabalho seja dedicado à atuação dentro das unidades de saúde, a maior parte do seu tempo é dedicado ao trabalho na comunidade. É importante que, a cada dia o ACS elabore um roteiro e prepare o seu material de trabalho. O previsto no PSF é que eles façam uma visita mensal a cada família e que, esta quantidade pode ser maior devido a problemas que as pessoas apresentem. Entretanto, há muitas variáveis que podem alterar a sua rotina, desde as intempéries, a recusa das famílias em atendê-los, o aumento momentâneo da violência no local, entre outros. Outro aspecto que interfere na sua rotina está ligado à falta de alguma pessoa a uma consulta marcada, a algum exame, ou a um grupo educacional. Isto requer novos agendamentos, novas negociações para conseguir vaga e, muitas vezes, tratar do descontentamento das pessoas pois, não é fácil agendar novas ações pois há uma grande sobrecarga do sistema.

58 O tempo de trabalho destes profissionais não se restringe à jornada programada, em muitas situações precisam alongar a sua estada na unidade de saúde ; levam exames, receitas médicas, material para coleta de exames, para entregarem às famílias durante o seu trajeto para casa ; levam documentos para trabalhar em casa e, muitas vezes, são abordados na rua ou são procurados em casa à noite ou no final de semana.

59 Além de todas estas atividades, estão previstas ações de promoção à saúde distintas dos grupos educativos centrados em alguma patologia (ex. hipertensão, câncer de mama, entre outros) e em aspectos de higiene. Os ACSs têm como objetivos, desenvolver ações que envolvam passeios, ginástica, teatro, música, dependendo das suas competências e das condições que encontram para desenvolvê-las.

60 A partir desta apresentação sucinta dos resultados obtidos por Mascia e colaboradores (2007) é possível se entender as dificuldades para que se possa criar indicadores sobre as atividades de trabalho dos ACSs, uma vez que muito do que fazem fica invisível, não é passível de quantificação, sobretudo porque se trata de um trabalho de imersão em uma determinada comunidade e que, em princípio, eles devem tratar de um espectro muito amplo de necessidades das pessoas.

\subsection{Dos resultados da ação em psicodinâmica do trabalho (baseado em Lancman et al., 2007)}

61 Trabalhar no PSF traz impactos significativos para estes trabalhadores, sobretudo porque estão construindo uma identidade profissional que difere de maneira significativa das profissões de saúde mais tradicionais e, sobretudo porque é um tipo de atividade de trabalho que não tem uma caracterização aceita socialmente. De certa forma, todos os integrantes das equipes PSF vivem uma transformação significativa no que diz respeito ao seu papel social, todas as identidades profissionais tradicionais são questionadas por este modo diferenciado de construir as ações em saúde pública. Assim como, no caso da ergonomia, a ênfase aqui será dada para o trabalho dos ACSs.

62 Os ACSs, que não tem uma capacitação profissional específica se defrontam com uma realidade bastante complicada, pois as necessidades da população são muito grandes e, 
os parâmetros para uma atuação que possa ser considerada como de boa qualidade e que seja de fato útil, ainda não são claros.

No discurso destes trabalhadores ficam evidentes estes desafios. Para eles se defrontar com uma proposta de trabalho que acompanha o ciclo de vida da população traz dimensões para a relação de serviço muito distintas das tradicionais. Acompanhar significa conviver com as necessidades, com os bons e maus resultados dos atendimentos, com a evolução das famílias, com o nascimento, com a morte, com a violência, entre tantas outras facetas da vida de uma população. Ser ACSs significa estar em contato permanente com estas questões, significa trabalhar com compaixão e, sobretudo significa não deixar para lá. Eles não podem se ater a um ato técnico enquadrado em um ambiente específico, eles estão trabalhando quase sempre, uma vez que, além de trabalhar, vivem na comunidade, são vizinhos das pessoas pelas quais são responsáveis.

Um dilema que eles vivenciam está ligado ao fato de trabalharem na incerteza com relação a o que priorizar como ações, há uma série de possibilidades e muitas dificuldades para que consigam, de fato, decidir o que fazer frente às necessidades da população, sobretudo porque há muita carência com relação aos recursos disponíveis. Segundo eles é muito doloroso propor algo que não vai acontecer, abrir uma possibilidade de acesso a um sistema de saúde que, no final das contas, não vai prover os serviços necessários. É como se "tirassem da fila física e colocassem numa fila de papel". As pessoas não querem esperar, as pessoas não concordam que as atividades de promoção sejam, de fato eficazes. Há toda uma experiência sendo construída com a população, experiência esta que é pautada de sucessos e insucessos. Entretanto, o que mais lhes aparece é o insucesso, é a frustração de não ter conseguido, é o sentimento de culpa de não ter conseguido uma consulta de especialista, um exame complementar e achar que, por causa disto é, em parte responsável, pela ausência de tratamento. Há uma grande dificuldade para re-encontrar as pessoas das famílias quando não obtiveram sucesso nas suas ações, isto é muito pior nos casos em que a pessoas vem a falecer.

Sentem que o trabalho deles não tem de fato limites e que vivem as contradições da sociedade em todos os momentos da jornada de trabalho e ao longo de todo o seu tempo, se sentem constantemente invadidos pelo trabalho.

O envolvimento com a comunidade transcende uma atuação profissional clássica em muitos sentidos, além do tempo e do espaço que não controlam, sentem que o fato de conviverem com os problemas das famílias lhes faz sentirem profundamente humanos. Acompanhar o ciclo de vida das pessoas, significa ir além do nascimento e da morte, pois a família estará lá. Conviver com a perda de alguém significa também se ocupar das pessoas na ausência de quem já faleceu. Tudo isto tem impacto na vivência do seu trabalho.

67 Ainda dentre as questões ressaltadas por Lancman e colaboradores (2007), citamos alguns outros dilemas vividos: "Como lidar com as impossibilidades que, muitas vezes, são muito semelhantes aos seus próprios problemas ? Como esquecer a miséria social e humana que presenciam? Como não pensar na inoperância do sistema em atender algum caso que sabem poderá se agravar pela falta de atendimento, nos períodos em que não estão trabalhando ? Como não interagir quando se é abordado na feira, na igreja, em festas ou outros espaços sociais, como não responder quando se é abordado 
no trajeto para o trabalho ou quando procurado em casa ? Como não receber as pessoas na sua casa se elas os recebem nas suas?

Por outro lado, já existem algumas estratégias para tentar minimizar o risco e o seu sofrimento. Para tal, buscam constituir uma rede de relações na comunidade que os ajuda a se proteger e a evitar situações mais perigosas. Desenvolvem condutas de prudência para tanto. Por outro lado, já há sinais da construção de estratégias defensivas, através da busca de um certo distanciamento, de procurar não saber, principalmente quando não podem fazer nada para as pessoas e, também procuram evitar o contato com situações comprometedoras, principalmente aquelas que envolvem violência, como agressões. Vivem o paradoxo da necessidade de se envolverem e a necessidade de se distanciarem para se defender.

A questão da identidade profissional para os ACSs é um ponto crítico, como se trata de um novo tipo de trabalho ainda há muitas dúvidas no que diz respeito a o que são. São pessoas da comunidade que trabalham para favorecer o acesso aos cuidados à saúde? São pessoas que representam o Estado e trazem tanto uma mensagem de prevenção e promoção da saúde quanto anunciam os limites do serviço público em atender as demandas dos munícipes? São um elo entre comunidade e sistema de saúde e, ao mesmo tempo, não podem ser considerados como meros integrantes da comunidade nem como um agente do Estado. $O$ agente tem uma profissão, ou a sua atividade não pode ser considerada como uma atividade profissional ? Afinal o que são ? Para quem trabalham ?". Isso mostra as dificuldades para construírem uma identidade mais clara e definida, pois em última instância, ao ocuparem a fronteira entre o sistema de saúde e comunidade, ficam no limbo, em um não-lugar, estão na "berlinda" (Lancman, Uchida, Sznelwar \& Jardim, 2007).

70 Apesar de viverem uma série de desafios que lhes causam sofrimento, e de viverem com este sentimento de ambigüidade com relação à sua identidade profissional, expressam satisfação com o seu trabalho, uma vez que o PSF, abre perspectivas muito interessantes no que diz respeito à construção de novas práticas, que permitem o desenvolvimento pessoal e profissional. A margem de manobra que encontram para desenvolver suas atividades e a possibilidade de construírem relações no âmbito das equipes de trabalho e na comunidade, abre uma perspectiva muito interessante com relação às possibilidades de encontrarem satisfação no seu trabalho. Apesar das ambigüidades e da frustração devida aos insucessos, encontram muito espaço para realizarem atividades consideradas como úteis pela comunidade. 0 espaço de liberdade de ação que encontram ainda seria uma possibilidade de transformar o sofrimento em ações efetivas com o objetivo de trazer melhores resultados. Isto evita impasses que poderiam transformar este sofrimento em sofrimento patogênico. Há espaço para o desenvolvimento da astúcia para conseguirem melhores resultados, assim como há espaço dentro das equipes para se expressarem e para construírem melhores relações de cooperação. Por outro lado, há o risco de caírem num certo ativismo para tentarem dar conta de tudo, ou mesmo de se tornarem "cínicos" frente ao sofrimento dos outros.

71 Para finalizar esta parte do artigo, onde foram apresentados os resultados da pesquisa sobre o trabalho das equipes do PSF e, com mais ênfase no trabalho dos ACSs, serão apresentadas algumas conclusões propostas pelos autores desta pesquisa.

72 Segundo Sznelwar e Abrahão (2007b) é importante que se entenda e se dissemine a experiência do PSF para que, se possa concretizar a implementação do programa, sobretudo se for considerada a realidade vivida pelos trabalhadores das equipes em 
confrontação com as necessidades da população e com as condições propiciadas para o desenvolvimento das ações previstas e não previstas. O diálogo constante entre aquilo que se propõe a partir de diretrizes dos gestores da saúde e a realidade vivida é importante para que o programa tenha continuidade.

A partir dos resultados mostrados neste estudo é importante, segundo estes autores, compreender o PSF sob olhares que englobem pontos de vista onde os atores estão constantemente interagindo criando e recriando maneiras de trabalhar. Estas maneiras de trabalhar também devem servir para promover a saúde e o desenvolvimento profissional dos trabalhadores. Note-se que os trabalhadores já mostram sinais de sobrecarga de trabalho, através de queixas, mais ou menos esparsas, de um aumento do absenteísmo, da rotatividade e de queixas de distúrbios psíquicos.

Propiciar condições para que os ACSs e os outros profissionais da equipe obtenham sucesso nas suas ações é estratégico, principalmente se forem consideradas as condições materiais para tal, mas sobretudo que seja de fato implantada uma rede eficaz de atendimento, prevenção e promoção para que se alcance os objetivos do Sistema Único de Saúde no Brasil.

“A demanda crescente da população pelos serviços do PSF é um sinal de sucesso, ao mesmo tempo é um indicador preocupante. Uma vez que se for ultrapassada a capacidade de trabalho das equipes, o programa pode entrar em decadência." (Sznelwar e Abrahão, 2007b).

\section{Discussão final}

75 A pesquisa feita junto a trabalhadores do PSF mostra a importância de se discutir a questão do trabalhar levando-se em conta aquilo que acontece na realidade e, sobretudo criando uma cooperação com os projetistas e gestores de programas como este para se poder agir no sentido de propiciar condições para que o sistema seja sustentável. 0 ponto de vista aqui defendido sobre o que seria sustentável tem a ver com a continuidade de um programa desta importância e envergadura para o desenvolvimento social de um país como o Brasil, isto é, que sejam atingidos os objetivos. Entretanto, para tal, é necessário que o trabalho dos integrantes das equipes seja também visto, projetado e gerenciado a partir de um ponto de vista sustentável. Como explicitado anteriormente, o ponto de vista sobre um trabalho sustentável, está contido nas propostas da ergonomia e da psicodinâmica do trabalho. Portanto, não se trata de uma novidade em si, apenas uma tentativa de reafirmar que qualquer sistema de produção que seja designado como sustentável, deverá considerar os pontos de vista defendidos por estes domínios de conhecimento e de ação. (Daniellou, 1996; Dejours, 1985, 2003, 2004a ; Wisner, 2004 ; Guerin et al. 2001).

76 O diálogo com os projetistas e gestores deve começar nas definições estratégicas. No caso do PSF, como de qualquer outro sistema de produção e, mais especificamente, no caso de serviços prestados à população, trata-se de um serviço público que, portanto, tem dentre seus pressupostos a universalidade e a equidade. Entretanto um serviço público não existe em si, ele resulta das condições reais de implantação e gestão do serviço (Derani, 2002). Para esta autora os princípios gerais que cercam as ações do Estado estão estabelecidos na Constituição, mas qualquer implantação de um serviço público depende de uma relação de forças e de condições em um nível micro, isto é, 
onde este de fato acontece. Haveria portanto uma necessidade de se criar um diálogo baseado no que de fato ocorre, tanto no que diz respeito às condições de atuação, como nos resultados obtidos, que podem servir para melhorar os processos de decisão nos níveis locais e, também nos níveis mais macro da gestão dos sistemas.

Fica aqui mais evidente a questão relacionada à dificuldade de se prever aquilo que vai acontecer na realidade, pois a experiência de cada equipe depende não apenas daquilo que lhes foi designado como missão, mas também na relação de serviço a ser construída com a população. Trata-se de um sistema que se constrói e se reconstrói continuamente, os pressupostos são gerais e norteiam as ações, mas aquilo que ocorre, e sobretudo os esforços e as adaptações necessárias para se garantir que o programa exista, depende dos esforços das equipes.

Para estes autores, o projetado consiste na definição de elementos como localização, instalações, arranjo físico de atendimento, sistemas de informação, equipamentos de apoio, medidas de avaliação/controle de qualidade e produtividade, capacidade produtiva, extensão da participação do cliente no processo e definição dos papéis dos prestadores de serviços e de suas tarefas.

Outros pontos de vista nos ajudam a compreender melhor esta questão do serviço, como a importância do conceito de relação de serviço (Hubault, 2002). Ainda, segundo Zarifian (2001), é importante que se considere nas práticas de gestão o valor dos serviços sob a ótica do usuário e a importância dos eventos na dinâmica das operações da produção do serviço. Para Maggi (2006), a dinâmica das operações é constituída através de processos de produção e do trabalho como espaços nos quais os sujeitos agem e decidem. Em concordância com ponto de vista deste autores, seria importante que as propostas dos planejadores e dos gestores, devem também estar o mais possível coladas na realidade vivida pelos trabalhadores que estão em contato direto com a população desservida.

No que diz respeito aos resultados desta pesquisa trazidos pelas abordagens em ergonomia e em psicodinâmica do trabalho, é de fundamental importância que se compreenda melhor a realidade do trabalhar para que, de fato, se possa falar em um programa sustentável, ancorado em atividades de trabalho que permitam visar a promoção da saúde dos trabalhadores, assim como a da população e, também propiciar condições para o desenvolvimento profissional e para a realização de si por parte dos integrantes das equipes PSF.

81 Apesar de, haver uma proximidade entre estas duas áreas de conhecimento, há que se manter as diferenças com relação às metodologias empregadas e às ações propostas, é importante se respeitar do recorte teórico/epistemológico que cada uma delas faz do objeto de estudo, o trabalhar. Uma questão interessante surge quanto aos lugares que a ergonomia e a psicodinâmica ocupam no âmbito das áreas que estudam o trabalho.

82 Pode-se perguntar então se esta questão deve-se à incompletude característica das diferentes ciências. Se assim o fosse, bastaria juntar as duas abordagens para que fosse possível reconstruir o humano no trabalho na sua globalidade. Esta seria, a nosso ver uma solução simplista que desconsideraria todo o debate existente entre estas duas áreas do conhecimento.

83 A partir destas considerações, julgamos importante fazer avançar os estudos empíricos e os conceitos que possam ajudar a compreender o trabalho em seus vários aspectos. Nesse sentido, é fundamental promover um diálogo entre os diversos campos de 
investigação, em especial, a ergonomia e a psicodinâmica do trabalho, buscando apreender possíveis complementaridades, confluências e/ou divergências e incompatibilidades. No nosso entender, isto permitirá, não só estudar situações específicas, mas também, subsidiar a ampliação do campo de pesquisa teórico que por sua vez possibilitará novas práticas e de formas de intervenção na realidade da produção.

84 Ainda para reforçar a questão do trabalho sob um ponto de vista sustentável, propomos a incorporação dos pontos de vista que a seguir :

Falzon discute a questão do durável ou do sustentável em ergonomia, a partir de um ponto de vista do desenvolvimento das possibilidades de escolha por parte das pessoas, isto é, em um espaço de liberdade com relação aos objetivos e critérios relativos ao seu trabalho, isto é, aumentando a sua "capabilidade", conceito que ele empresta de Amartya Sen. Para o autor, a inscrição no durável das ações ergonômicas estaria ligada à perspectiva de que, a partir delas, o trabalho seja considerado como uma dimensão estratégica para a gestão. Isto seria fruto dos elementos não tangíveis de uma ação ergonômica (Falzon, 2005).

Para Hubault (2004b) seria importante pensar no sustentável, quando discute a gestão dos risco, considerando-se a necessidade de ancorar as decisões no quotidiano, isto é, naquilo que "acontece", em relação com a invocação àquilo que "deve ou deveria ser" (da regra, universo da engenharia), da projeção naquilo que "será ou deverá" (da estratégia, universo da gestão). Para o autor é necessário que se inscreva a idéia da prevenção calcada no conceito de situação de trabalho, mantendo uma atenção naquilo que emerge, e que se construa uma governabilidade do sistema, a partir de uma postura clínica, criando instrumentos de gestão orientados pela atividade, foco de atenção da ergonomia.

87 Fica patente também a importância de ressaltar aquilo que faz sentido para as pessoas. Atingir resultados significativos ao trabalhar, evitando o aparecimento de sofrimento patológico, conseqüentemente de doenças as mais diversas é um desafio. Para os gestores, fica a questão de evitar a criação e a imposição de trabalhos desprovidos de sentido. Para os trabalhadores há vários desafios para que consigam se desenvolver enquanto profissionais, onde a avaliação do seu trabalho, o reconhecimento daquilo que fazem é uma necessidade para desenvolver sentimentos ligados à utilidade e de beleza das suas ações (Dejours, 2003). Além disso, há o desafio constante para manterem os espaços profissionais para a promoção da sua saúde que, depende fundamentalmente da promoção da saúde da população com a qual trabalham.

Discutir a importância de se desenvolver um olhar sustentável com relação ao trabalho que sirva como base para se construir programas de saúde pública que também obtenham sucesso e, de fato possam se tornar elementos centrais de um sistema de saúde que seja unificado e que garanta a justiça e equidade a serviço da população como o PSF, passa por uma incorporação das contribuições da psicodinâmica do trabalho e da ergonomia, sem ser excludente com relação a outras disciplinas. Os resultados obtidos nas pesquisas mostradas neste artigo corroboram este posicionamento e a importância de se incluir os resultados destes campos de investigação e de ação que tenham o trabalho como central, para o projeto e a gestão destes sistemas. Portanto o que se propõe aqui não é uma mistura de abordagens mas, sobretudo facilitar aos atores envolvidos a apropriação de conceitos e de resultados que lhes possam ser úteis. Isto produz uma tensão que já se mostrou útil pois advém de abordagens que têm como base 
a realidade constituinte de programas de saúde pública, com o PSF e que trazem ao espaço público diferentes pontos de vista que são úteis para enriquecer o conhecimento e, sobretudo, melhor balizar os processos de decisão.

\section{BIBLIOGRAFIA}

Arendt, H. (1987). A Condição Humana. Rio de Janeiro : ForenseUniversitária.

Béguin, P. (2006). Taking activity into account during the design process. In R. N. Pikaar \& E.A.P. Koningsveld (Eds). Meeting Diversity in Ergonomics, Proceedings of the IEA2006 Congress, July 2006, Maastricht, Netherlands.

Brasil (1998). Saúde da Família : uma estratégia para reorientação do modelo assistencial. Brasília : Ministério da Saúde.

Carayon, P. (2006). Human factors of complex sociotechnical systems. Applied Ergonomics, 37, 525-535.

Clot, Y. (1999). La fonction psychologique du travail. Paris : PUF.

Cru, D. \& Dejours, C. (1983). Savoir-faire de prudence dans les métiers du bâtiment. Cahiers médicaux-sociaux, 27, 239-247.

Daniellou, F. (1996). Introduction. Questions épistémologiques autour de l'ergonomie. In F. Daniellou (Dir), L'ergonomie en quête de ses principes (pp. 1-17). Toulouse : Octares.

Dejours, C. (1985). Construire sa santé. In B. Cassou, Les risques du travail (pp. 18 - 21). Paris : La Decouverte.

Dejours, C. (1987). A loucura do trabalho : estudo de psicopatologia do trabalho. São Paulo : Cortez/Oboré.

Dejours, C. (2003). L'évaluation du travail à l'épreuve du réel. Critiques des fondements de l'evaluation. Paris : INRA.

Dejours, C. (2004a). Addendum, da psicopatologia à psicodinâmica do trabalho. In S. Lancman, L. I. Sznelwar (Orgs), Christophe Dejours : da psicopatologia à psicodinâmica do trabalho (pp. 47-104). Rio de Janeiro : Paralelo15/FIOCRUZ.

Dejours, C. (2004b). Sofrimento e prazer no trabalho : A abordagem pela psicopatologia do trabalho. In S. Lancman, L. I. Sznelwar (Orgs), Christophe Dejours : da psicopatologia à psicodinâmica do trabalho (pp. 141-156). Rio de Janeiro : Paralelo15/FIOCRUZ.

Dejours, C. (2004c). A metodologia em psicodinâmica do trabalho. In S. Lancman, L. I. Sznelwar (Orgs), Christophe Dejours : da psicopatologia à psicodinâmica do trabalho (pp. 105-126). Rio de Janeiro : Paralelo15/FIOCRUZ.

Dejours, C., Abdoucheli, E. \& Christian, J. (1994). Psicodinâmica do Trabalho : contribuição da Escola Dejouriana à Análise da Relação Prazer, Sofrimento e Trabalho. São Paulo : Ed. Atlas S.A.

Derani, C. (2002). Privatizações e Serviços Públicos : as ações do Estado na produção econômica. São Paulo : Editora Max Limonad. 
Falzon, P. (1996). Des objectifs de l'ergonomie. In F. Daniellou (dir), L'ergonomie en quête de ses principes (pp. 233-242). Toulouse : Octarès.

Falzon, P. (2005). Ergonomie, conception et développement. Actes du 40ème Congrès de la SELF (pp. 30-39). Saint Denis de la Réunion : Éditions de l'ANACT.

Guérin, F., Laville, A., Daniellou, F., Duraffourg, F. \& Kerguelen, A. (2001). Compreender o trabalho para transformá-lo : A prática da ergonomia. São Paulo : Editora Blücher.

Guillant, L. Le (1984). La névrose des téléphonistes. In Groupe de Recherche Louis Le Guillant (Orgs.), Quelle psychiatrie pour notre temps? (pp. 379-391). Toulouse : Érès. (texto original de 1956).

Hubault, F. (2002). L'intervention (ergonomique) comme relation de service. In F. Hubault (Dir.), La relation de service, opportunités et questions nouvelles pour l'ergonomie. Toulouse : Octarès.

Hubault, F. (2004a). Do que a ergonomia pode fazer a análise ? In F. Daniellou (Coord.), A ergonomia em busca de seus princípios : debates epistemológicos (pp. 105-140). São Paulo : Edgard Blücher. Hubault, F. (2004b). Choisir un modèle du risque qui permet d'y répondre, durablement. Communication séminaire ANACT - Les conditions d'une prévention durable des TMS.

Hubault, F. (2008). Le travail dans la gestion : tensions et contradictions. In R. Beaujolin-Belle, P. Louart, \& M. Parlier, Le travail, un défi pour la GRH (pp. 22-40). Lyon : ANACT.

Imada, A. S. (2005). Macroergonomic contributions : Understanding the causes of our success. In P. Carayon, M. Robertson, B. Kleiner \& P.L.T Hoonakker (Eds.), Human Factors in Organizational Design and Management - VIII (pp. 35-42). Santa Monica : IEA Press.

Kleiner, B.M. (2006). MacroErgonomics Analysis and Design. In R. N. Pikaar \& E.A.P. Koningsveld (Ed), Meeting Diversity in Ergonomics, Proceedings of the IEA2006 Congress, July 2006, Maastricht, Netherlands.

Kogi, K. (2006). Participatory methods effective for ergonomic workplace improvement. Applied Ergonomics, 37, 547-554.

Lancman, S. \& Uchida, S. (2003). Trabalho e subjetividade. Caderno de Psicologia Social e do Trabalho, 6, 77-88.

Lancman, S., Uchida, S., Sznelwar, L. I. \& Jardim, T. A. (2007). Agente Comunitario de Saude : Um trabalhar na berlinda - Estudo de psicodinâmica do trabalho. Travailler, 17, 71-96.

Lancman, S., Uchida, S., Sznelwar, L. I., Jardim, T. A. \& Gasparo, S. (2007). o trabalhar no Programa saúde da família : um estudo em psicodinâmica do trabalho. In L.I. Sznelwar (org). Programa Saúde da Família : Pontos de vista da organização de serviços, da ergonomia e da psicodinâmica do trabalho. In A.L.A. Vianna (Coord.), Abordagens e desafios no estudo do trabalho no PSF. Inquérito com usuários e profissionais, percepção dos gestores e estudos sobre o Programa de Saúde da Família (v. 3, pp. 207-228). São Paulo : CEDEC.

Maggi, B. (2006). Do agir organizacional : Um ponto de vista sobre o trabalho, o bem estar, a aprendizagem. São Paulo : Blucher.

Mascia, F. L., Vezza, F. M. G., Watanabe, M., Destefano, R. L., Mesquita, R. \& Zuccolotto, S. (2007). O trabalho no Programa Saúde da Família sob a ótica da ergonomia. In L.I. Sznelwar (org). Programa Saúde da Família : Pontos de vista da organização de serviços, da ergonomia e da psicodinâmica do trabalho. In A.L.A. Vianna (Coord.), Abordagens e desafios no estudo do trabalho no PSF. Inquérito com usuários e profissionais, percepção dos gestores e estudos sobre o Programa de Saúde da Família (v. 3, pp. 173-205). São Paulo : CEDEC. 
Molinier, P. (1995). Psychodynamique du travail et identité sexuelle. Thése de doctorat en Psychologie. Paris : Conservatoire National des Arts et Metiers.

Molinier, P. (2001). Souffrance et théorie de l'action. Travailler, 7, 131-146. Montmollin, M. de (septembre, 1993). Compétences, charge mentale, stress : peut-on parler de santé "cognitive" ? XXVIIIème congrés de la SELF, Genève.

Morin, E. (1998). Ciência com consciência. Rio de Janeiro : Bertrand Brasil.

Murphy, J. B. (1993). The moral economy of labor. Aristotelian themes in economic theory. New Haven : Yale University Press.

Noulin, M. (1992). Ergonomie. Paris : Techniplus.

Rabardel, P. \& Béguin, P. (2005). Instrumented mediated activity : from subject development to anthropocentric design. Theoretical Issues in Ergonomics Science, 7, 5, 429-461.

Silva, M. T., Silveira, C., Quaggio, F. M. \& Colameo, G. (2007). Análise da organização do trabalho no Programa Saúde da Família. In

L.I. Sznelwar (Org), Programa Saúde da Família : Pontos de vista da organização de serviços, da ergonomia e da psicodinâmica do trabalho. In A.L.A. Vianna (Coord.), Abordagens e desafios no estudo do trabalho no PSF. Inquérito com usuários e profissionais, percepção dos gestores e estudos sobre o Programa de Saúde da Família (v. 3, pp. 129-172). São Paulo : CEDEC.

Silveira, C. (1999). O Significado da Prática Profissional em Unidade Básica de Saúde : um estudo da cultura organizacional no Centro de Saúde Escola Barra Funda. São Paulo : Faculdade de Medicina da Universidade de São Paulo.

Sznelwar, L. I. \& Massetti, M. (2002). Agressões ao corpo e/ou sofrimento psiquico ? Um estudo construído a partir da experiência de trabalhadores com LER/DORT. Travailler, 8, 153-176.

Sznelwar, L. I \& Abrahão, J. I. (2007a). Introdução : abordagens e desafios no estudo do trabalho no PSF. In L.I. Sznelwar (Org), Programa Saúde da Família : Pontos de vista da organização de serviços, da ergonomia e da psicodinâmica do trabalho. In A.L.A. Vianna (Coord.), Abordagens e desafios no estudo do trabalho no PSF. Inquérito com usuários e profissionais, percepção dos gestores e estudos sobre o Programa de Saúde da Família (v. 3, pp. 107-128). São Paulo : CEDEC.

Sznelwar, L. I. \& Abrahão, J. I.(2007b). Conclusão : a produção e o trabalho no PSF : uma realidade a ser entendida e disseminada. In L.I. Sznelwar (Org), Programa Saúde da Família : Pontos de vista da organização de serviços, da ergonomia e da psicodinâmica do trabalho. In A.L.A. Vianna (Coord.), Abordagens e desafios no estudo do trabalho no PSF. Inquérito com usuários e profissionais, percepção dos gestores e estudos sobre o Programa de Saúde da Família (v. 3, pp. 229-236). São Paulo : CEDEC.

Terssac, G. (de) \& Maggi, B. (2004). O trabalho e a abordagem ergonômica. In F. Daniellou (Coord.), A ergonomia em busca de seus princípios : debates epistemológicos (pp. 79-104). São Paulo : Edgard Blücher.

Wisner, A. (2004). Questões epistemológicas em ergonomia e em análise do trabalho. In F. Daniellou (Coord.), A ergonomia em busca de seus princípios : debates epistemológicos (pp. 29-55). São Paulo : Edgard Blücher.

Zarifian, P. (2001). Valor dos serviços e estratégia de serviço. In M. Salerno (Org.), Relação de serviço, produção e avaliação. São Paulo : Editora Senac. 


\section{RESUMOS}

O tema da sustentabilidade, cada vez mais presente no mundo da produção é geralmente apresentado como uma questão voltada para o meio ambiente e, também para questões de responsabilidade social. A proposta deste artigo é, em primeiro lugar, propor uma discussão sobre a sustentabilidade onde a questão do trabalho se torna central. Trata-se de propor um ponto de vista sustentável para tratar da questão do trabalhar, numa tentativa de trazê-la para o centro do debate. Apesar de ser uma proposta que busca incluir na agenda da sustentabilidade a questão do trabalho, não se trata de um tema novo. Diferentes disciplinas que tratam do trabalho, mesmo que não explicitem a questão de um trabalho sustentável, tem na sua constituição conceitual este tema. No caso aqui presente, a proposta de construção de um ponto de vista sustentável sobre o trabalho propõe um debate com diferentes disciplinas que tratam do projeto e da gestão produção e do trabalho e está baseada na ergonomia da atividade e na psicodinâmica do trabalho. $O$ argumento aqui proposto é baseado em um estudo de caso junto a trabalhadores que atuam no Programa Saúde da Família no Brasil, mais especificamente os Agentes Comunitários da Saúde. Os resultados deste estudo mostram aspectos fundamentais do trabalho destas pessoas e, evidenciam que, para desenvolver programas de saúde pública que possam ser considerados como sustentáveis, isto é, que perdurem e que possam atingir os seus objetivos, é fundamental que o trabalhar seja tratado sob a perspectiva da sua inscrição no tempo, da construção da saúde e do desenvolvimento pessoal e profissional.

El tema de la sustentabilidad, cada vez más presente en el mundo de la producción, generalmente aparece como una problemática ligada al medio ambiente y a las cuestiones de la responsabilidad social. Este artículo propone, en primer lugar, una discusión sobre la sustentabilidad en la cual el trabajo resulta central. Se trata de proponer un punto de vista sustentable para abordar la cuestión del trabajar, de manera tal de hacer de esta cuestión el eje central del debate. A pesar de tratarse de una propuesta que busca incluir en la agenda de la sustentabilidad al trabajo, no resulta ser una novedad ya que diferentes disciplinas que se ocupan del trabajo, incluso cuando no lo hagan en forma explicita, el problema del trabajo sustentable se encuentra presente en sus bases conceptuales. En el caso que acá se presenta, la propuesta de construcción de un punto de vista sustentable sobre el trabajo, plantea el debate a través de la ergonomía de la actividad y la psicodinamica del trabajo, disciplinas que abordan las cuestiones de los proyectos, de la gestión de la producción y del trabajo. La argumentación que acá se desarrolla esta basada en el estudio de un caso de trabajadores, específicamente los Agentes Comunitarios de Salud, que intervienen en el Programa Comunitario de Salud Familiar, en Brasil,. Los resultados de este estudio muestran aspectos fundamentales del trabajo de estas personas, en el sentido de que para desarrollar programas de salud pública que puedan ser considerados sustentables, es decir, que perduren y que puedan alcanzar sus objetivos, es fundamental que el trabajar sea abordado desde la perspectiva de su inscripción en el tiempo, de la construcción de la salud y del desarrollo personal y profesional.

La discussion à propos de ce qui serait durable ou soutenable devient chaque fois plus présente dans le monde de la production. Il s'agit toutefois presque toujours de l'associer à des questions liées à l'environnement et à la responsabilité sociale. Cet article veut placer le travail au centre de ce débat ; il s'agit de construire un pont entre ce qui serait considéré comme soutenable et la question du travail. La proposition d'inclure dans l'agenda du soutenable la question du travail n'est pas une nouveauté. Car, même si différentes disciplines qui traitent du travail n'explicitent pas la question du travail soutenable, leur constitution conceptuelle la contient souvent. La construction d'un point de vue soutenable sur le travail que nous proposons met en débat les disciplines qui s'occupent du projet et de la gestion de la production et du travail, et table sur les contributions de l'ergonomie de l'activité et de la psychodynamique du travail. L'argumentation 
proposée est basée sur une étude de cas développée auprès des travailleurs du Programme Santé de la Famille, au Brésil (les Agents Communautaires de Santé). Les résultats de cette étude révèlent des aspects fondamentaux du travail et mettent aussi en évidence que, pour développer des programmes de santé publique qui seraient considérés comme soutenables, i.e. qui durent et atteignent leur objectifs, il serait fondamental que le travail soit considéré dans son inscription dans le temps, dans la perspective de la construction de la santé, du développement personnel et professionnel.

The theme of sustainability, increasingly present in the world of production, is generally presented as an issue involving the environment and social responsibility. The purpose of this article is first to propose a discussion on sustainability in which the issue of work become central, by proposing a sustainable vision for treating work, in an attempt to bring this issue to the center of the debate. Despite this proposal seeking to include work on the agenda of sustainability, this is not a new issue. The different disciplines that deal with work include this theme in their conceptual framework, even if they do not make sustainable work an explicit issue. In the case presented here, the proposal to create a sustainable view of work proposes a discussion among the different disciplines that deal with production and work design and management and is based in the ergonomics of activity and the psychodynamics of work. The argument proposed is based on a case study carried out with workers in the Family Health Program in Brazil and, more specifically, the Community Health Agents. The results of the study reveal fundamental aspects of the work these people do and show that, to develop public health programs that can be considered sustainable, i.e. that endure and are able to achieve their objectives, it is fundamental that work is treated from the perspective of its inscription in time, of the construction of health and personal and professional development.

\section{ÍNDICE}

Palavras-chave: trabalho sustentável, ergonomia, psicodinâmica do trabalho, sistema público de saúde

Mots-clés: travail soutenable, ergonomie, psychodynamique du travail, système public de santé Palabras claves: trabajo sustentable, ergonomía, psicodinamica del trabajo, sistema publico de salud

Keywords: sustainable work, ergonomics, psychodynamics of work, public health system

\section{AUTOR}

\section{LAERTE IDAL SZNELWAR}

Departamento de Engenharia de Produção da Escola Politécnica, Universidade de São Paulo, Av. Prof. Almeida Prado, trav. 2, no 128, CEP 05508-900, São Paulo, SP, Brasil

laertesz@usp.br

Manuscrito recebido em : Fevereiro/2009

Aceite após peritagem em : Maio/2009 